\title{
Prognostic significance of baseline T cells, B cells and neutrophil-lymphocyte ratio (NLR) in recurrent ovarian cancer treated with chemotherapy
}

Jon Røikjær Henriksen ${ }^{1,2^{*}}$ D, Line Nederby ${ }^{3}$, Frede Donskov ${ }^{4}$, Marianne Waldstrøm ${ }^{2,5}$, Parvin Adimi ${ }^{1}$, Anders Jakobsen ${ }^{1,2}$ and Karina Dahl Steffensen ${ }^{1,2}$

\begin{abstract}
Purpose: Biomarkers are needed to guide treatment decisions in recurrent ovarian cancer, as a high proportion of patients do not benefit from treatments. Data on immune subsets in patients receiving chemotherapy are scarce. We investigated the impact of T cells, B cells, neutrophils and the neutrophil-lymphocyte ratio (NLR) in ovarian cancer patients receiving palliative chemotherapy.

Methods: Blood samples were collected prospectively at baseline in recurrent ovarian cancer $(N=72)$ receiving chemotherapy. T cells, B cells, neutrophils, and NLR were analyzed. Primary and secondary endpoints were overall survival (OS) and treatment response, respectively. Cut-offs for $T$ and $B$ cells were predefined.

Results: In patients with low vs. high T and B cells counts, OS was 6.1 months vs 12.0 months $(P=0.017)$ and 6.1 months vs 12.0 months $(P=0.011$, respectively. Low $T$ and $B$ cells analyzed as continuous variables were also associated with unfavorable OS, $P=0.011$ and $P=0.007$, respectively. Neutrophils had no significant prognostic impact. Median NLR was 4.1. High vs. low NLR was associated with poor survival, 7.4 months vs. 15.9 months $(P=$ 0.012). In multivariate analysis including platinum sensitivity, number of prior lines of chemotherapy, and performance status, high NLR remained an independent poor prognostic factor HR: $2.17(95 \% \mathrm{Cl} 1.21-3.88)(P=$ 0.009). High NLR was also significantly associated with lack of response, OR 0.15 ( $95 \% \mathrm{Cl}$ : $0.04-0.51)(P=0.002)$.

Conclusion: In recurrent ovarian cancer patients undergoing palliative chemotherapy, low $T$ and $B$ lymphocyte counts had an unfavorable prognostic impact. High NLR was associated with lack of response and a poor prognosis, and the parameter may be used in patient counselling and treatment decisions.
\end{abstract}

Keywords: Ovarian cancer, B cells, T cells, Neutrophils, NLR

\footnotetext{
* Correspondence: jon.henriksen@rsyd.dk

'Department of Oncology, Vejle Hospital - University Hospital of Southern Denmark, Vejle, Denmark

${ }^{2}$ Faculty of Health Sciences, Institute of Regional Health Research, University of Southern Denmark, Odense, Denmark

Full list of author information is available at the end of the article
}

C C The Author(s). 2020 Open Access This article is licensed under a Creative Commons Attribution 4.0 International License, which permits use, sharing, adaptation, distribution and reproduction in any medium or format, as long as you give appropriate credit to the original author(s) and the source, provide a link to the Creative Commons licence, and indicate if changes were made. The images or other third party material in this article are included in the article's Creative Commons licence, unless indicated otherwise in a credit line to the material. If material is not included in the article's Creative Commons licence and your intended use is not permitted by statutory regulation or exceeds the permitted use, you will need to obtain permission directly from the copyright holder. To view a copy of this licence, visit http://creativecommons.org/licenses/by/4.0/. The Creative Commons Public Domain Dedication waiver (http://creativecommons.org/publicdomain/zero/1.0/) applies to the data made available in this article, unless otherwise stated in a credit line to the data. 


\section{Introduction}

Recurrent ovarian cancer represents a therapeutic challenge. Advances in the area of PARP-inhibitors have improved the outcome for some patients [1], but chemotherapy options for platinum-resistant disease or third line treatment are of minimal or no benefit $[2,3]$. Checkpoint immunotherapy has been promising in other malignancies, but it has only shown a modest effect as single agent in ovarian cancer [4]. Despite poor efficacy and risk of toxicity from chemotherapy in the recurrent metastatic setting, most patients request further treatment. In these situations, a subjective clinician assessment of a patient's physical state is the only tool to foresee if a patient will benefit from further chemotherapy. No biomarkers to support the decision exist and are certainly warranted.

The understanding of the immune system in patients receiving chemotherapy is scarce. Still, the notion of tumor infiltrating leukocytes with both tumor promoting and antitumor capabilities places immune cells as potential biomarkers and targets for therapy [5]. In the blood, the neutrophil-lymphocyte ratio (NLR) has been used as a surrogate marker for the balance between an unfavorable impact of neutrophils and a favorable effect of lymphocytes [6]; a high NLR has been associated with poor survival in several malignancies, including ovarian cancer [7-9]. A high NLR value can be obtained by either a high neutrophil count or a low lymphocyte count; a detailed analysis of the relative contribution to the NLR-equation has not been performed in ovarian cancer. Although a few studies have shown a relationship between high baseline neutrophils and poor survival in ovarian cancer $[10,11]$, the role of circulating neutrophils in the disease is still unclear.

The most abundant type of lymphocyte subset is the $\mathrm{T}$ cell. Several studies have shown a positive prognostic impact of a high concentration of tumor-infiltrating $\mathrm{T}$ cells in various malignancies, including ovarian cancer [12-21].

Despite their positive prognostic value in the tumor and their contribution to the NLR equation, the impact of circulating $\mathrm{T}$ cells as a solitary biomarker has not been investigated in ovarian cancer.

The B cell is another central lymphocyte. They are key elements of the humoral immunity and the source of antibodies. Antibodies against tumor antigens have been found in serum from cancer patients, indicating some B cell antitumor activity [22], while on the other hand, a tumor-promoting function of B cells has been suggested as well [23-27]. The literature on the prognostic impact of tumor-infiltrating B cells has been diverging [28-31], and no investigations have been made on the prognostic impact of circulating B cells in ovarian cancer.

The aim of this study was to quantify major immune subsets included in the NLR equation, neutrophils, $\mathrm{T}$ cells, and B cells, in blood from recurrent ovarian cancer patients sampled immediately prior to chemotherapy.

\section{Methods}

\section{Patient cohort}

Study participants were consecutive patients with recurrent metastatic ovarian cancer undergoing palliative chemotherapy at the Department of Oncology, University Hospital of Southern Denmark, Vejle, between December 2016 and October 2018. They were treated according to institutional and national guidelines with the goal of life prolongation and symptom relief. Only non-resectable patients were included. Patients eligible for palliative chemotherapy were included with no further in- or exclusion criteria. Blood samples were drawn 0-7 days prior to commencement of treatment, which was defined as baseline. Imaging was performed every eight to 12 weeks, depending on the treatment regimen, and CA-125 was analyzed routinely at each treatment cycle. The immune cell status had no influence on the choice of treatment.

All patients provided signed informed consent before any study procedure. The Ethics Committee (S-20160049) and the Danish Data Protection Agency (16/28860) approved the study.

\section{Blood analysis}

Enumeration of neutrophils was conducted on a Sysmex XN-9000 instrument (Sysmex, Kobe, Japan) as part of the routine blood testing.

Quantification of lymphocytes, B cells, and T cells was performed by flow cytometry. Fresh venous blood was collected in BD vacutainer EDTA tubes (BD Biosciences, San Jose, CA, USA). Whole blood surface staining was performed in BD Trucount $^{\circ}$ Tubes using BD Multitest ${ }^{\circ}$ CD3 FITC/CD16 + CD56 PE/CD45 PerCP/CD19 APC (Clones: SJ25C1, SK7, B73.1, NCAM16.2, 2D1) (BD Biosciences). Subsequently, BD FACS Lysing Solution (BD Biosciences) was used for lysing erythrocytes. Samples were analyzed within $2 \mathrm{~h}$ on a BD FACS Canto II (BD Biosciences), and FlowJo version $\mathrm{X}$ (Flowjo, Ashland, OR) was used for data analysis.

$\mathrm{T}$ cells were defined as $\mathrm{CD} 45^{\text {high }}$, side scatter $^{\text {low }}$, CD3+, and CD16-/56-. B cells were defined as CD45 ${ }^{\text {high }}$, side scatter $^{\text {low }}$, CD3-, CD16-/56-, and CD19+ (Fig. 1).

Baseline lymphocyte, $\mathrm{T}$, and $\mathrm{B}$ cell values were collected in 69 patients. Neutrophil baseline values were obtained in all 72 patients. Missing values were due to either missed blood drawings $(N=1)$ or technical error in sample preparation $(N=2)$.

The applied neutrophil cut-off level originated from a previous report [10], showing baseline neutrophil counts higher than $3.9 \times 10^{9}$ cells/L to be prognostically unfavorable. The $\mathrm{T}$ cell cut-off level was based on reference values by Bisset et al. [32], i.e., an abnormally low level of $\mathrm{T}$ cells $\left(<0.53610^{9}\right.$ cells/L) and a normal/high level of $\mathrm{T}$ cells $\left(\geq 0.53610^{9}\right.$ cells $\left./ \mathrm{L}\right)$. The same reference was used for the B cell cutoff level, i.e., an abnormally low 

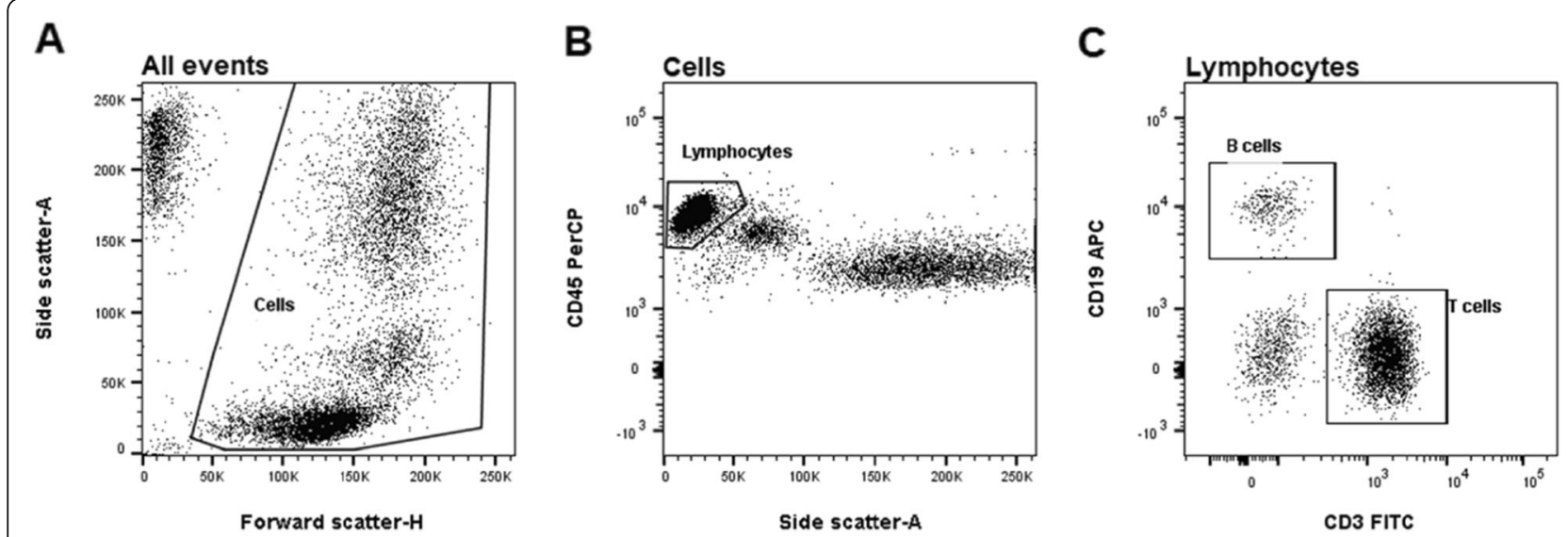

Fig. 1 Flow cytometry identifying B and T cells. a Forward scatter and side scatter allow for the identification of the cell subset by size and granularity. b Side scatter and CD45 staining differentiate the lymphocytes. c Fluorochrome-conjugated antibodies enable differentiation of specific cell types in the lymphocyte gate: $T$ cells CD3+ and B cells CD19+

level of B cells $\left(<0.07210^{9}\right.$ cells/L) and a normal/high level of B cells ( $\geq 0.07210^{9}$ cells/L). The cut-off for NLR was defined as the median value.

\section{Statistical analysis}

The Pearson Chi-square test was used to evaluate the association between $\mathrm{T}$ cell count, B cell count, neutrophil count, and clinical factors. The primary endpoint was overall survival (OS) calculated from the date of the baseline blood drawing to death or last follow-up.

Kaplan-Meier plots illustrated survival, and the log-rank test analyzed the significance of differences between variables. Median overall survival was used for comparison of survival according to NLR and the level of neutrophil, T cell, and B cell count. Multivariate cox regression analysis tested the independent prognostic significance with the 95\% confidence interval (CI). The proportional hazard assumption was tested and complied with all cox regression analyses. Treatment response was defined by either CA125 or the Response Evaluation Criteria in Solid Tumors (RECIST) 1.1 following the Gynecological Cancer Intergroup (GCIG) criteria [33]. Binary logistic regression tested the relation between treatment response and immune factors. As a secondary aim, immune cell counts were also tested as continuous variables using univariate cox-regression.

Descriptive, correlational, survival, and regression analyses were performed using STATA version $16^{\circ}$ (StataCorp, College Station, TX, USA).

\section{Results}

\section{Patients}

The study included 72 patients at a median age of 69 years (range 47-92). High-grade serous carcinoma (HGSC) was the dominating histopathologic type $(N=$ $61,84 \%)$. Patients had received one to five lines of chemotherapy prior to inclusion; 32 patients (44\%) had received one previous line of therapy. Twenty-four patients (33\%) were platinum-sensitive. Table 1 shows the baseline patient characteristics. Baseline CA-125 level, histology, number of previous lines of chemotherapy, present chemotherapy, and performance status were evenly distributed between patients according to immune cell subset level, with the exception that more patients with low baseline $\mathrm{B}$ and $\mathrm{T}$ cells, respectively, had received more lines of chemotherapy (Table 1). The median OS for all patients was 8.9 months (95\% CI: 7.415.6). At the time of analysis, 21 patients were still alive with a median follow-up time of 19.3 months (range 11.7-33.3). A total of 21 patients (29\%) achieved a treatment response according to the GCIG criteria [33].

\section{Neutrophils}

The median blood neutrophil count was $5.0 \times 10^{9}$ cells/L (range 1.5-20.7). At baseline, 51 patients had a high neutrophil count above the predefined cut-off of $3.9 \times$ $10^{9}$ cells/L cut-off. The neutrophil count was not significantly associated with OS, neither when analyzed as a dichotomized (Fig. 2) nor as a continuous variable HR: 1.03, (95\% CI: 0.96-1.11), $(P=0.357)$.

\section{T cells}

The median blood $\mathrm{T}$ cell count at baseline was $0.801 \times$ $10^{9}$ cells/L (range: $187-2808$ ). A low T cell count (predefined cut-off $<0.536 \times 10^{9}$ cells/L) was associated with poor survival. Patients with low $\mathrm{T}$ cell levels $(N=19)$ had median OS of 6.1 months (95\% CI: 3.4-10.0) compared to median 12.1 months (95\% CI: 8.3-17.2) in patients with normal/high $\mathrm{T}$ cell level $(N=50)(P=0.017)$ (Fig. 2). Decreasing T cell count as a continuous variable was significantly associated with poor OS in the Cox regression analysis, HR: $1.09(P=0.011) \quad$ (stepwise 100 
Table 1 Baseline patient characteristics

Median age
(range)
P value
Median CA-125 kU/L
(range)
P value
Histology
High-grade serous carcinoma
Low-grade serous carcinoma
Endometrioid
Mucinous
P value

\begin{tabular}{lllll}
$\begin{array}{l}\text { Baseline Cohort } \\
(N=72)\end{array}$ & $\begin{array}{l}\text { High neutrophil count* } \\
(N=51)\end{array}$ & $\begin{array}{l}\text { Low T cell count } \\
(N=19)\end{array}$ & $\begin{array}{l}\text { Low B cell count*** } \\
(N=21)\end{array}$ & $\begin{array}{l}\text { High NLR*** } \\
(N=34)\end{array}$ \\
\hline 69 & 68 & 71 & 72 & 68 \\
$(47-92)$ & $(47-92)$ & $(50-84)$ & $(59-92)$ & $(47-92)$ \\
& 0.852 & 0.248 & 0.116 & 0.657 \\
332 & 488 & 330 & 616 & 487 \\
$(6-30,072)$ & $(6-30,072)$ & $(11-30,072)$ & $(13-10,325)$ & $(6-30,072)$ \\
& 0.411 & 0.443 & 0.443 & 0.443
\end{tabular}

Previous lines of chemotherapy

1
$2-3$
$4-5$
$P$ value

$\begin{array}{ll}61(84 \%) & 45(88 \%) \\ 4(6 \%) & 3(6 \%) \\ 4(6 \%) & 2(4 \%) \\ 3(4 \%) & 1(2 \%) \\ & 0.366\end{array}$

$18(95 \%)$
$0(0 \%)$
$0(0 \%)$
$1(5 \%)$
0.486

$18(85 \%)$
$0(0 \%)$
$2(10 \%)$
$1(5 \%)$
0.203

$31(88 \%)$

$\begin{array}{ll}32(44 \%) & 22(43 \%) \\ 31(43 \%) & 23(45 \%) \\ 9(13 \%) & 6(12 \%) \\ & 0.391\end{array}$

$\begin{array}{lll}4(21 \%) & 4(19 \%) & 11(32 \%) \\ 12(63 \%) & 15(71 \%) & 19(54 \%) \\ 3(16 \%) & 2(10 \%) & 5(14 \%) \\ 0.068 & 0.011 & 0.122\end{array}$

\section{Platinum sensitive}

No
Yes

$\begin{array}{ll}48(67 \%) & 33(65 \%) \\ 24(33 \%) & 18(35 \%) \\ & 0.582\end{array}$

$\begin{array}{lll}14(74 \%) & 15(71 \%) & 25(71 \%) \\ 5(26 \%) & 6(29 \%) & 10(29 \%) \\ 0.446 & 0.579 & 0.395\end{array}$

Performance status

Performance status
2
P value

$\begin{array}{ll}46(64 \%) & 31(61 \%) \\ 26(36 \%) & 20(39 \%) \\ & 0.393\end{array}$

\section{Treatment regimen}

\begin{tabular}{|c|c|c|c|c|c|}
\hline Carboplatin & $10(14 \%)$ & $9(18 \%)$ & $3(16 \%)$ & $4(19 \%)$ & $8(23 \%)$ \\
\hline Carboplatin + lipos. Dox. & $13(18 \%)$ & $8(16 \%)$ & $2(11 \%)$ & $2(10 \%)$ & $2(6 \%)$ \\
\hline Carboplatin + paclitaxel & $1(1 \%)$ & $1(2 \%)$ & $0(0 \%)$ & $0(0 \%)$ & $0(0 \%)$ \\
\hline Liposomal doxorubicin & $14(20 \%)$ & $10(19 \%))$ & $4(21 \%)$ & $2(10 \%)$ & $8(23 \%)$ \\
\hline Topotecan & $16(22 \%)$ & $11(21 \%)$ & $6(31 \%)$ & $5(23 \%)$ & $9(25 \%)$ \\
\hline Treosulfan & $12(17 \%)$ & $8(16 \%)$ & $2(11 \%)$ & $5(23 \%)$ & $5(14 \%)$ \\
\hline Paclitaxel & $2(3 \%)$ & $2(4 \%)$ & $1(5 \%)$ & $1(5 \%)$ & $1(3 \%)$ \\
\hline Gemcitabine & $2(3 \%)$ & $1(2 \%)$ & $0(0 \%)$ & $0(0 \%)$ & $0(0 \%)$ \\
\hline Vinorelbine & $1(1 \%)$ & $1(2 \%)$ & $1(5 \%)$ & $1(5 \%)$ & $1(3 \%)$ \\
\hline Bevacizumab & $1(1 \%)$ & $0(0 \%)$ & $0(0 \%)$ & $1(5 \%)$ & $1(3 \%)$ \\
\hline$P$ value & & 0.642 & 0.579 & 0.251 & 0.062 \\
\hline \multicolumn{6}{|l|}{ Maintenance treatment\# } \\
\hline Bevacizumab & $8(11 \%)$ & $4(8 \%)$ & $2(11 \%)$ & $1(5 \%)$ & $2(6 \%)$ \\
\hline Olaparib & $3(4 \%)$ & $3(6 \%)$ & $0(0 \%)$ & $0(0 \%)$ & $0(0 \%)$ \\
\hline$P$ value & & 0.125 & 0.301 & 0.490 & 0.301 \\
\hline
\end{tabular}

Baseline patient demographics and disease characteristics according to immune cell level. $P$ values are derived from chi-square test. ${ }^{*}$ Neutrophil count cut-off 3.9 cells $/ \mathrm{mL}$.**T cells count cut-off: 536 cells/ $\mu \mathrm{L}$. *** B cell count cut-off: 72 cells $/ \mu \mathrm{L}$. **** NLR cut-off: 4.1 . \# Of the 72 patients, 11 recieved maintenance treatment in addition to the primary treatment regimen 

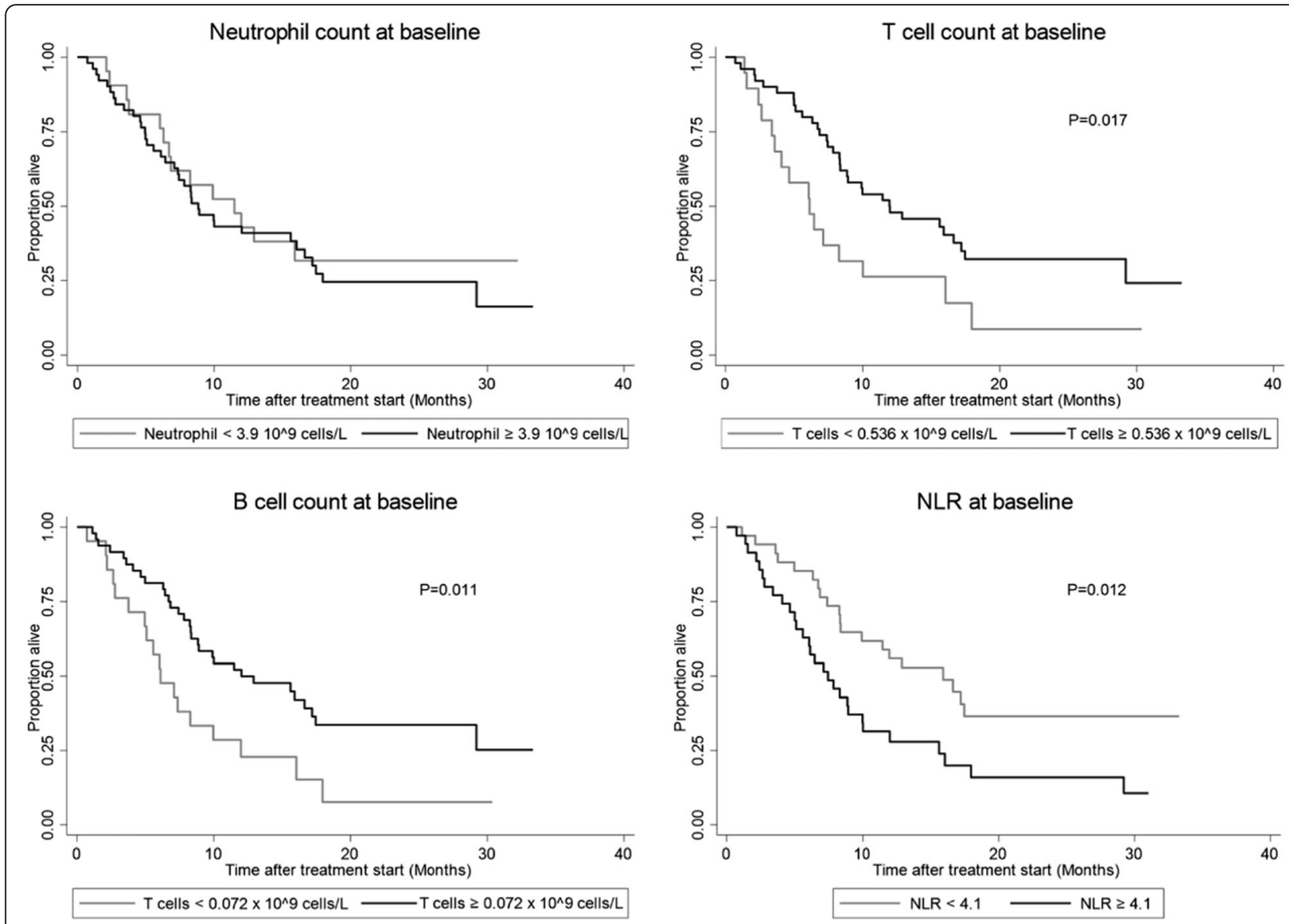

Fig. 2 Prognostic impact of baseline immune subsets in recurrent ovarian cancer patients receiving chemotherapy. A favorable prognostic impact was seen with high baseline T cells and B cells. Baseline blood neutrophils had no prognostic impact. High baseline neutrophil lymphocyte ratio (NLR) was associated with a poor prognosis

cells $/ \mu \mathrm{L}$ ), which corresponds to a $9 \%$ increase in risk of death for every decrease of $100 \mathrm{~T}$ cells $/ \mu \mathrm{L}$.

\section{B cells}

The median blood B cell count at baseline was $109 \times 10^{9}$ cells/L (range: 12-392). A low B cell count (predefined cut-off $<0.072 \times 10^{9}$ cells/L) was associated with poor survival. Patients with a low B cell level $(N=22)$ had a median OS of 6.1 months (95\% CI: 3.8-10.0) compared to 12.0 months in patients with a normal/high $\mathrm{B}$ cell level $(N=47)$ (95\% CI: 8.3-17.5, $P=0.011)$ (Fig. 2). Decreasing B cell count as a continuous variable was significantly associated with poor OS at baseline HR: 1.05 $(P=0.007)$ (stepwise 10 cells $/ \mu \mathrm{L})$, corresponding to a $5 \%$ increase in the risk of death for every decrease of $10 \mathrm{~B}$ cells $/ \mu \mathrm{L}$.

\section{NLR}

The median NLR was 4.1 (range 0.9-37.9). High NLR was associated with poor survival. Patients with high NLR $(N=35)$ vs. low NLR $(N=34)$ had a median OS of
7.4 months (95\% CI: $5.1-10.0)$ and 15.9 months (95\% CI: 8.3-not reached), respectively, $(P=0.012)$ (Fig. 2). The NLR as a continuous variable was not significantly associated with OS, HR: $1.02(P=0.121)$.

\section{Relation to treatment response}

In patients with high NLR, four of 35 (11\%) obtained response according to the GCIG criteria, whereas in patients with low NLR, 16 of 34 (47\%) achieved response, odds ratio 0.15 (95\% CI: $0.04-0.51, P=0.002$ ). No significant association between treatment response and neutrophils, B cells, or T cells was found.

\section{Multivariate analysis}

Multivariate analysis was performed to evaluate the independent significance of the variables. As neutrophils, $\mathrm{T}$ cells, and B cells are inherent parts of the NLR, these subsets were therefore not included as single markers in the multivariate analysis. Clinical factors significant in univariate analysis were incorporated (platinum sensitivity, number of prior lines of chemotherapy, and performance 
status). Histology, CA-125 level, age, and treatment regimen were not significant in univariate analysis and therefore not incorporated. The multivariate analysis revealed high NLR as an independent factor for poor overall survival, HR: 2.17, (95\% CI 1.21-3.88), $P=0.009$, (Table 2).

\section{Discussion}

Recurrent ovarian cancer is marked by an inherent resistance to therapy with low response rates and poor survival. Cancer cell drug-resistance mechanisms play a critical role [34, 35]. A growing notion is that reduced immune surveillance and immune escape also plays a crucial role in cancer progression [36, 37]. Yet, evidence suggests that certain types of chemotherapy may in fact reboost tumor immune response by inducing immunogenic cell death [20]. Evidently, the immune system plays a central role in ovarian cancer, yet immunological investigations have primarily focused on $\mathrm{T}$ cells and macrophages infiltrated in the tumor tissue. In this study, we investigated the quantity of essential circulating immune cell subtypes; neutrophils, B cells, and T cells in ovarian cancer with the perspective of improving the treatment strategy.

The present study confirmed the independent prognostic importance of the NLR and also suggested a significant impact of $B$ and $T$ cells. The immune subset analyses revealed that low levels of $\mathrm{T}$ cells and $\mathrm{B}$ cells were associated with short survival. In contrast, blood neutrophils per se were of no prognostic importance in patients with ovarian cancer. We also demonstrated a high NLR of 4.1 as a strong independent prognostic factor for poor OS and a strong factor for predicting lack of response. Thus, the subset analyses underscored the importance of low levels of $\mathrm{T}$ and $\mathrm{B}$ cells in the NLR-

Table 2 Multivariate analysis

\begin{tabular}{lll}
\hline & OS & \\
\cline { 2 - 3 } & $\mathrm{HR}(95 \% \mathrm{Cl})$ & \\
\hline Platinum sensitive & & \\
No & Ref. & 0.102 \\
Yes & $0.59(0.32-1.11)$ & \\
Prior lines of chemotherapy & \\
$1-3$ & Ref. & 0.001 \\
$4-5$ & $3.82(1.68-8.72)$ & \\
Performance status & & \\
$0-1$ & Ref. & \\
2 & $2.93(1.63-5.28)$ & \\
NLR & & 0.001 \\
Low & Ref. & \\
High & $2.17(1.21-3.88)$ & \\
\hline
\end{tabular}

Multivariate Cox regression analysis. Hazard ratios (HR) derived from multivariate Cox regression analysis. NLR cut-off defined from the median (4.1) equation, whereas blood neutrophils did not contribute with significant impact. To the best of our knowledge, a subset analysis has not previously been performed of the contributing factors in the NLR equation in ovarian cancer patients treated with chemotherapy.

Treatment of recurrent ovarian cancer remains a clinical challenge. Most available chemotherapy regimens only have modest effect in terms of response and survival and at the expense of toxicity in most patients. The management of ovarian cancer needs a higher degree of individualization with incorporation of clinically significant factors in the treatment decision making process. This is best exemplified by the use of age as a determining factor. Currently, high age most often affects the choice of treatment in ovarian cancer, although it is not a significant contributing factor in terms of survival, neither in this study nor in previously published literature $[38,39]$. In the current study, the significant factors associated with overall survival were number of prior lines of chemotherapy, performance status, and NLR. Performance status is often the only major factor guiding the prediction as to whether the patient will benefit from chemotherapy, but it is subject to poor inter-rater reliability [40]. Hence, the strength of a biomarker such as the NLR compared to performance status is its objective indication. Our data suggest that in addition to performance status, high NLR may be instrumental in patient counseling and involvement in the treatment decision making. Our study showed a high NLR above 4.1 to be associated with a very short survival time. This parameter could be considered in the evaluation of a patient in relation to a new line of chemotherapy.

The focus of the present study was baseline blood values measured just before commencing treatment. The clinical significance of values at this time point is of relevance to the decision of whether to initiate therapy or save patients from ineffective treatment. Usually, these decisions are made after 3 cycles when treatment efficacy is typically evaluated, and patients have undergone 9-12 weeks of treatment already. In clinical practice, it is also relevant to stop ineffective treatment as early as possible, and biomarkers more effective than CA-125 are needed in this setting. Longitudinal sampling of blood could have indicated the potential of the investigated immune cell subsets during treatment, but this was not within the scope of the current study.

Previous studies found an association between a high level of circulating neutrophils and poor survival in cancer patients [10, 11, 41], but the present analysis showed no prognostic impact of the neutrophils count in recurrent ovarian cancer. By contrast, the data were in line with our recent assessment of tumor infiltrating neutrophils in ovarian cancer patients, in which we were unable to identify a negative or positive prognostic impact 
of the neutrophils [21]. A correlation between high NLR and poor survival in ovarian cancer patients in relation to debulking surgery and adjuvant chemotherapy has been demonstrated [9]. Importantly, in the present study we were able to confirm high NLR as a strong negative prognostic factor in the recurrent setting.

A notion of an anti-tumor effect of lymphocytes is well established in ovarian cancer tissue, while research on the prognostic impact of $\mathrm{T}$ cells in the blood has mainly focused on regulatory $\mathrm{T}$ cells [42-44] and only sparsely in ovarian cancer [45]. Our results confirmed a significant, favorable prognostic impact of $\mathrm{T}$ lymphocyte subsets, both assessed as continuous variables and dichotomized by predefined cut-offs. This encourages more studies on the use of checkpoint inhibitors in ovarian cancer as $\mathrm{T}$ cell responses are known to be unleashed by this type of treatment.

The prognostic importance of the B cell count in cancer is unresolved and has mainly been investigated in tumor tissue [28-31, 46]. We used a predefined cut-off and analyzed the prognostic impact both as a continuous and a dichotomized variable. Our analysis pointing towards $\mathrm{B}$ cells as contributors to the antitumor activity could indicate an important role of humoral immunity in ovarian cancer, and further research in the area is warranted. An anti-tumor effect of B cells could have implications for future immunotherapy strategies in ovarian cancer since immune checkpoint inhibitors are known to enhance the proliferation of B cells and their production of antibodies [47-50]. Despite disappointing results of single-agent checkpoint inhibitors in ovarian cancer $[4,51]$, the prognostic importance of $\mathrm{B}$ and $\mathrm{T}$ cells may support further testing of this group of agents.

Although our study provides interesting results, it has several limitations. Firstly, the small number of patients limits statistical significance and prevents subgroup analysis. In future research, it would be interesting to study the prognostic impact of the investigated immune cells in different histological subgroups, in separate treatment regimens, and in different treatment lines, as the prognostic impact may be conditioned by biological differences in the subgroups. Obviously, chronic illnesses could be hypothesized to affect the immune cell count, and lack of inclusion of this parameter in the current study could be considered a limitation. Also, the types of previous chemotherapy regimens and time elapsed since the last treatment may affect the immune cell count, as patients progressing or recurring during or shortly after previous chemotherapy may be immunologically different. In line with the above mentioned statistical limitations of a relatively small cohort, these factors were not included in order to reduce the number of variables.

Though limited by the patient flow of a small size institution, this study also has strengths. The experiments were conducted prospectively, and analyses were based on predefined cut-offs previously published by others. Furthermore, we were able to confirm the prognostic role of NLR, and our finding that blood neutrophils have no prognostic impact in ovarian cancer is supported by recent intratumoral results from our group [21].

In the context of the limitations of the study, it is essential to emphasize that the current study is exploratory. Full implementation of the results into clinical practice requires verification, preferably in a larger, randomized study.

\section{Conclusions}

In recurrent ovarian cancer patients treated with palliative chemotherapy, low $\mathrm{T}$ and B lymphocyte counts had an unfavorable prognostic impact. High NLR was associated with lack of response and a poor prognosis, and the parameter may be used in patient counseling and treatment decisions.

\section{Acknowledgments}

We are thankful for the logistic work by study nurse Yvette Schandorf and the technical laboratory assistance by Sara Egsgaard and Bjarne Damgaard Andreassen. Frede Donskov received a research grant from the Health Research Foundation of Central Denmark Region.

\section{Authors' contributions}

Karina Dahl Steffensen, Frede Donskov, Anders Jakobsen, Line Nederby, Marianne Waldstrøm, and Jon Røikjær Henriksen contributed to the study conception and design. Parvin Adimi, Line Nederby, and Jon Røikjær Henriksen performed material preparation, data collection, and analysis. Jon Røikjær Henriksen drafted the initial manuscript and all authors contributed to and approved the final manuscript.

\section{Availability of data and materials}

According to Danish legislation on data protection individual participant data cannot be shared unless fully anonymized. Due to the nature of the stud dataset this is not possible.

\section{Ethics approval and consent to participate}

All patients provided signed informed consent before any study procedure, which included consent for publication. The Ethics Committee (S-20160049) and the Danish Data Protection Agency (16/28860) approved the study.

\section{Competing interests}

The authors declare that they have no conflict of interest. The research was solely publicly funded.

\section{Author details \\ ${ }^{1}$ Department of Oncology, Vejle Hospital - University Hospital of Southern Denmark, Vejle, Denmark. ${ }^{2}$ Faculty of Health Sciences, Institute of Regional Health Research, University of Southern Denmark, Odense, Denmark. ${ }^{3}$ Biochemistry and Immunology, Vejle Hospital - University Hospital of Southern Denmark, Vejle, Denmark. ${ }^{4}$ Department of Oncology, Aarhus University Hospital, Aarhus, Denmark. ${ }^{5}$ Department of Pathology, Vejle Hospital - University Hospital of Southern Denmark, Vejle, Denmark.}

Received: 16 January 2020 Accepted: 6 May 2020

Published online: 15 May 2020

References

1. Coleman RL, Fleming GF, Brady MF, et al. LBA3VELIA/GOG-3005: Integration of veliparib $(V)$ with front-line chemotherapy and maintenance in women with high-grade serous carcinoma of ovarian, fallopian tube, or primary 
peritoneal origin (HGSC). Ann Oncol. 2019;30(Supplement_5). https://doi. org/10.1093/annonc/mdz394.054.

2. Hanker LC, Loibl S, Burchardi N, et al. The impact of second to sixth line therapy on survival of relapsed ovarian cancer after primary taxane/ platinum-based therapy. Ann Oncol. 2012;23(10):2605-12. https://doi.org/10. 1093/annonc/mds203.

3. Francis J, Coakley N, Elit L, Mackay H. Gynecologic Cancer disease site group TGCDS. Systemic therapy for recurrent epithelial ovarian cancer: a clinical practice guideline. Curr Oncol. 2017;24(6):e540-6. https://doi.org/10.3747/co. 24.3824.

4. Matulonis UA, Shapira-Frommer R, Santin AD, et al. Antitumor activity and safety of pembrolizumab in patients with advanced recurrent ovarian cancer: results from the phase II KEYNOTE-100 study. Ann Oncol. 2019;30(7): 1080-7. https://doi.org/10.1093/annonc/mdz135.

5. Hanahan D, Weinberg RA. Review hallmarks of Cancer : the next generation. Cell. 2011;144(5):646-74. https://doi.org/10.1016/j.cell.2011.02.013.

6. Guthrie GJK, Charles KA, Roxburgh CSD, Horgan PG, McMillan DC, Clarke SJ. The systemic inflammation-based neutrophil-lymphocyte ratio: experience in patients with cancer. Crit Rev Oncol Hematol. 2013;88(1):218-30. https:// doi.org/10.1016/j.critrevonc.2013.03.010.

7. Templeton AJ, McNamara MG, Šeruga B, et al. Prognostic role of neutrophilto-lymphocyte ratio in solid tumors: A systematic review and meta-analysis. J Natl Cancer Inst. 2014;106(6). https://doi.org/10.1093/jnci/dju124.

8. Cho H, Hur HW, Kim SW, et al. Pre-treatment neutrophil to lymphocyte ratio is elevated in epithelial ovarian cancer and predicts survival after treatment. Cancer Immunol Immunother. 2009;58(1):15-23. https://doi.org/10.1007/ s00262-008-0516-3.

9. Huang Q, Zhou L, Zeng W-J, et al. Prognostic significance of neutrophil-tolymphocyte ratio in ovarian Cancer: a systematic review and meta-analysis of observational studies. Cell Physiol Biochem. 2017;41(6):2411-8. https://doi. org/10.1159/000475911.

10. Banerjee S, Rusti G, Paul J, et al. A multicenter, randomized trial of flat dosing versus intrapatient dose escalation of single-agent carboplatin as first-line chemotherapy for advanced ovarian cancer: an SGCTG (SCOTROC 4) and ANZGOG study on behalf of GCIG. Ann Oncol. 2013;24(3):679-87. https://doi.org/10.1093/annonc/mds494.

11. Carus A, Gurney H, Gebski V, et al. Impact of baseline and nadir neutrophil index in non-small cell lung cancer and ovarian cancer patients: assessment of chemotherapy for resolution of unfavourable neutrophilia. J Transl Med. 2013;11:189. https://doi.org/10.1186/1479-5876-11-189.

12. Pinto MP, Balmaceda C, Bravo ML, et al. Patient inflammatory status and CD4+/CD8+ intraepithelial tumor lymphocyte infiltration are predictors of outcomes in high-grade serous ovarian cancer. Gynecol Oncol. 2018;151(1): 10-7. https://doi.org/10.1016/j.ygyno.2018.07.025.

13. Hwang WT, Adams SF, Tahirovic E, Hagemann IS, Coukos G. Prognostic significance of tumor-infiltrating $T$ cells in ovarian cancer: a meta-analysis. Gynecol Oncol. 2012;124(2):192-8. https://doi.org/10.1016/j.ygyno.2011.09.039.

14. Sato E, Olson SH, Ahn J, et al. Intraepithelial CD8+ tumor-infiltrating lymphocytes and a high CD8+/regulatory T cell ratio are associated with favorable prognosis in ovarian cancer. Proc Natl Acad Sci U S A. 2005; 102(51):18538-43. https://doi.org/10.1073/pnas.0509182102.

15. Zhang L, Conejo-Garcia JR, Katsaros D, et al. Intratumoral T cells, recurrence, and survival in epithelial ovarian cancer. N Engl J Med. 2003;348(3):203-13. https://doi.org/10.1056/NEJMoa020177.

16. Ali HR, Provenzano E, Dawson S-J, et al. Association between CD8+ T-cell infiltration and breast cancer survival in 12439 patients. Ann Oncol. 2014; 25(8):1536-43. https://doi.org/10.1093/annonc/mdu191.

17. Mlecnik B, Tosolini M, Kirilovsky A, et al. Histopathologic-based prognostic factors of colorectal cancers are associated with the state of the local immune reaction. J Clin Oncol. 2011;29:610-8. https://doi.org/10.1200/JCO. 2010.30.5425.

18. Goode EL. Dose-response relationship of $\mathrm{cd} 8+$ tumor infiltrating lymphocytes and survival time in high-grade serous ovarian cancer hhs public access. JAMA Oncol. 2017;3(12):173290. https://doi.org/10.1001/ jamaoncol.2017.3290.

19. Hamanishi J, Mandai M, Abiko K, et al. The comprehensive assessment of local immune status of ovarian cancer by the clustering of multiple immune factors. Clin Immunol. 2011;141:338-47. https://doi.org/10.1016/j. clim.2011.08.013.

20. Lo CS, Sanii S, Kroeger DR, et al. Neoadjuvant chemotherapy of ovarian cancer results in three patterns of tumor-infiltrating lymphocyte response with distinct implications for immunotherapy. Clin Cancer Res. 2017;23(4): 925-34. https://doi.org/10.1158/1078-0432.CCR-16-1433.

21. Henriksen J, Donskov $F$, Waldstrøm $M$, et al. Tissue immune response in epithelial ovarian carcinoma. J Clin Oncol. 2019;37(15_suppl):2625. https:// doi.org/10.1200/jco.2019.37.15_suppl.2625.

22. Reuschenbach M, Von Knebel DM, Wentzensen N. A systematic review of humoral immune responses against tumor antigens. Cancer Immunol Immunother. 2009;58:1535-44. https://doi.org/10.1007/s00262-009-0733-4.

23. Yuen GJ, Demissie E, Pillai S. B lymphocytes and Cancer: a love-hate relationship. Trends Cancer. 2016;2(12):747-57. https://doi.org/10.1016/j. trecan.2016.10.010.

24. Gupta P, Chen C, Chaluvally-Raghavan P, Pradeep S. B Cells as an immuneregulatory signature in ovarian Cancer. Cancers. 2019;11(7). https://doi.org/ 10.3390/cancers11070894.

25. Ammirante M, Luo J-L, Grivennikov S, Nedospasov S, Karin M. B-cell-derived lymphotoxin promotes castration-resistant prostate cancer. Nature. 2010; 464(7286):302-5. https://doi.org/10.1038/nature08782.

26. Griss J, Bauer W, Wagner C, et al. B cells sustain inflammation and predict response to immune checkpoint blockade in human melanoma. Nat Commun. 2019;10(1):4186. https://doi.org/10.1038/s41467-019-12160-2.

27. de Visser KE, Korets LV, Coussens LM. De novo carcinogenesis promoted by chronic inflammation is B lymphocyte dependent. Cancer Cell. 2005;7(5): 411-23. https://doi.org/10.1016/J.CCR.2005.04.014.

28. Sasada T, Suekane $\mathrm{S}$. Variation of tumor-infiltrating lymphocytes in human cancers: controversy on clinical significance. Immunotherapy. 2011;3(10): 1235-51. https://doi.org/10.2217/imt.11.106.

29. Nelson BH. CD20 + B cells: the other tumor-infiltrating lymphocytes. J Immunol. 2010;185(9):4977-82. https://doi.org/10.4049/jimmunol.1001323.

30. Gentles AJ, Newman AM, Liu CL, et al. The prognostic landscape of genes and infiltrating immune cells across human cancers. Nat Med. 2015;21(8): 938-45. https://doi.org/10.1038/nm.3909.

31. Pagès F, Galon J, Dieu-Nosjean MC, Tartour E, Sautès-Fridman C, Fridman WH. Immune infiltration in human tumors: a prognostic factor that should not be ignored. Oncogene. 2010;29(8):1093-102. https://doi.org/10.1038/onc.2009.416.

32. Bisset LR, Lung TL, Kaelin M, Ludwig E, Dubs RW. Reference values for peripheral blood lymphocyte phenotypes applicable to the healthy adult population in Switzerland. Eur J Haematol. 2004;72(3):203-12. https://doi. org/10.1046/j.0902-4441.2003.00199.x.

33. Rustin GJS, Vergote I, Eisenhauer $E$, et al. Definitions for response and progression in ovarian cancer clinical trials incorporating RECIST 1.1 and CA 125 agreed by the gynecological Cancer intergroup (GCIG). Int I Gynecol Cancer. 2011;21(2):419-23. https://doi.org/10.1097/IGC.0b013e3182070f17.

34. Redmond KM, Wilson TR, Johnston PG, Longley DB. Resistance Mechanisms to Cancer Chemotherapy, vol. 5138; 2008.

35. Laganà AS, Colonese F, Colonese $\mathrm{E}$, et al. Cytogenetic analysis of epithelial ovarian cancer's stem cells: an overview on new diagnostic and therapeutic perspectives. Eur J Gynaecol Oncol. 2015;36(5):495-505.

36. Vinay DS, Ryan EP, Pawelec $G$, et al. Immune evasion in cancer: mechanistic basis and therapeutic strategies. Semin Cancer Biol. 2015;35(Suppl):S185-98. https://doi.org/10.1016/j.semcancer.2015.03.004.

37. Laganà AS, Sofo V, Vitale SG, Triolo O. Epithelial ovarian cancer inherent resistance: may the pleiotropic interaction between reduced immunosurveillance and drug-resistant cells play a key role? Gynecol Oncol Rep. 2016;18:57-8. https://doi.org/10.1016/j.gore.2016.09.004.

38. Vitale SG, Capriglione S, Zito G, et al. Management of endometrial, ovarian and cervical cancer in the elderly: current approach to a challenging condition. Arch Gynecol Obstet. 2019;299(2):299-315. https://doi.org/10. 1007/s00404-018-5006-z.

39. Schuurman MS, Kruitwagen RFPM, Portielje JEA, Roes EM, Lemmens VEPP, van der Aa MA. Treatment and outcome of elderly patients with advanced stage ovarian cancer: a nationwide analysis. Gynecol Oncol. 2018;149(2): 270-4. https://doi.org/10.1016/j.ygyno.2018.02.017.

40. Taylor AE, Olver IN, Sivanthan T, Chi M, Purnell C. Observer error in grading performance status in cancer patients. Support Care Cancer. 1999;7(5):332-5. https://doi.org/10.1007/s005200050271.

41. Donskov F. Immunomonitoring and prognostic relevance of neutrophils in clinical trials. Semin Cancer Biol. 2013;23(3):200-7. https://doi.org/10.1016/j. semcancer.2013.02.001.

42. Wolf AM, Wolf D, Steurer M, Gastl G, Gunsilius E, Grubeck-Loebenstein B. Increase of regulatory $T$ cells in the peripheral blood of cancer patients. Clin Cancer Res. 2003;9(2):606-12. 
43. Liyanage UK, Moore $\Pi$, Joo H-G, et al. Prevalence of regulatory T cells is increased in peripheral blood and tumor microenvironment of patients with pancreas or breast adenocarcinoma. J Immunol. 2002;169(5):2756-61. https://doi.org/10.4049/jimmunol.169.5.2756.

44. He Q, Li G, Ji X, et al. Impact of the immune cell population in peripheral blood on response and survival in patients receiving neoadjuvant chemotherapy for advanced gastric cancer. Tumor Biol. 2017;39(5): 101042831769757. https://doi.org/10.1177/1010428317697571.

45. Curiel TJ, Coukos G, Zou L, et al. Specific recruitment of regulatory T cells in ovarian carcinoma fosters immune privilege and predicts reduced survival. Nat Med. 2004;10(9):942-9. https://doi.org/10.1038/nm1093.

46. Zhou X, Su Y-X, Lao X-M, Liang Y-J, Liao G-Q. CD19+IL-10+ regulatory B cells affect survival of tongue squamous cell carcinoma patients and induce resting CD4+ T cells to CD4+Foxp3+ regulatory T cells. Oral Oncol. 2016;53: 27-35. https://doi.org/10.1016/j.oraloncology.2015.11.003.

47. Nishimura H, Minato N, Nakano T, Honjo T. Immunological studies on PD-1deficient mice: implication of PD-1 as a negative regulator for $\mathrm{B}$ cell responses. Int Immunol. 1998;10(10):1563-72. https://doi.org/10.1093/ intimm/10.10.1563.

48. Pioli C, Gatta L, Ubaldi V, Doria G. Inhibition of IgG1 and IgE production by stimulation of the B cell CTLA-4 receptor. J Immunol. 2000;165(10):5530-6. https://doi.org/10.4049/jimmunol.165.10.5530.

49. Thibult ML, Mamessier E, Gertner-dardenne J, et al. Pd-1 is a novel regulator of human B-cell activation. Int Immunol. 2013;25(2):129-37. https://doi.org/ 10.1093/intimm/dxs098.

50. Pardoll DM. The blockade of immune checkpoints in cancer immunotherapy. Nat Rev Cancer. 2012;12(4):252-64. https://doi.org/10. 1038/nrc3239.

51. Gaillard SL, Coleman RL. Identifying markers of immune response in ovarian cancer: does PD-L1 expression meet the mark? Ann Oncol. 2019;30(7):10258. https://doi.org/10.1093/annonc/mdz166.

\section{Publisher's Note}

Springer Nature remains neutral with regard to jurisdictional claims in published maps and institutional affiliations.

Ready to submit your research? Choose BMC and benefit from:

- fast, convenient online submission

- thorough peer review by experienced researchers in your field

- rapid publication on acceptance

- support for research data, including large and complex data types

- gold Open Access which fosters wider collaboration and increased citations

- maximum visibility for your research: over $100 \mathrm{M}$ website views per year

At $\mathrm{BMC}$, research is always in progress.

Learn more biomedcentral.com/submissions 